TABLE Lod scores (Z) for neurofibromatosis and the marker loci.

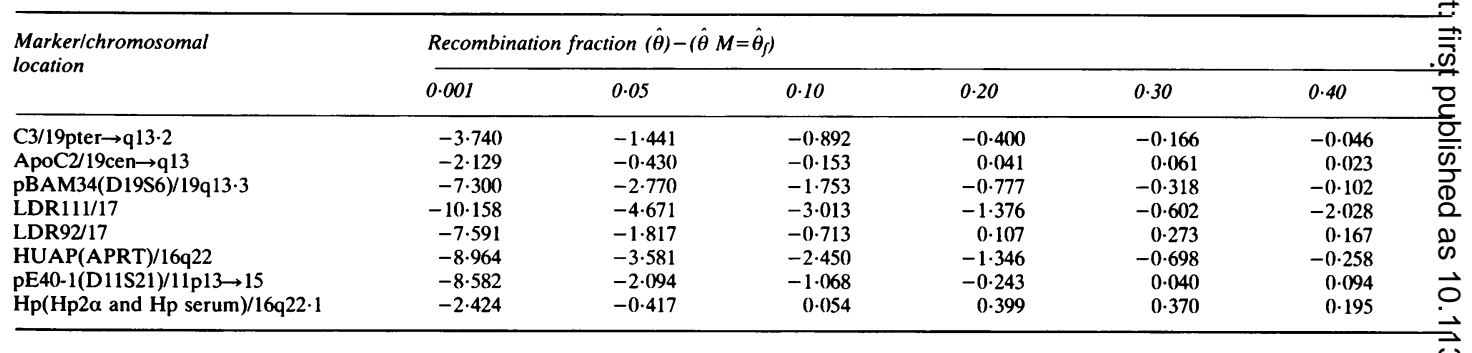

\section{Discussion}

These results represent our initial attempt to localise the gene for NF. At present, the data are inconclusive. We will continue to screen this pedigree and our other large multi-generation NF families for linkage until a successful linkage is found.

Funding for this project was provided by NIH Research Grant No 1 RO1 NS23008-01. The authors would like to thank the following for-generously supplying us with DNA probes for analysis: Drs Stephen Humphries (ApoC2), George Fey (C3), Peter Stambrook (HUAP), Nubuyo Maeda (Hp2 $\alpha$ ), and Thomas Glaser (pE40-1). The authors would also like to thank Laurita Melton, Patricia Watson, and Peggy Pate for their technical assistance in the preparation of this manuscript and the pedigree data. Finally, we would like to acknowledge the many NF family members without whose participa tion these studies would not have been possible.

References

Riccardi VM. Von Recklinghausen neurofibromatosis. N Eng Med 1981;305:1617-26.

2 Carey JC, Laub JM, Hall BD. Penetrance and variability neurofibromatosis: a genetic study of 60 families. Birth Defects 1979;XV(5B):271-81.

${ }^{3}$ McKusick VA. Mendelian inheritance in man. 6th ed. Ball more: Johns Hopkins University Press, 1983.

4 Ott J. Estimation of the recombination fraction in huma pedigrees: efficient computation of the likelihood for huma linkage studies. Am J Hum Genet 1974;26:588-97.

5 Willard HF, Skolnick MH, Pearson PL, Mandel JL. Report of the committee on human gene mapping by recombinant $\mathrm{EN} \mathbb{N}$ techniques. HGM8. Cytogenet Cell Genet 1985;40:360-490워

6 Davies KE. Human genetic diseases: a practical approzch. Oxford: IRL Press, 1986.

Correspondence and requests for reprints to Margaret A Pericak-Vance, Division of Neurologs? Department of Medicine, Duke University Medic\& Center, Durham, North Carolina 27710, USA.

\title{
Linkage analysis of peripheral neurofibromatosis to DNA markers on chromosome 8
}

\section{S R DIEHL*, M BOEHNKE†, F S COLLINS*, R P ERICKSON*, I J KAROLYI*, L M PLOUGHMAN†, M A PERICAK-VANCE} A S AYLSWORTH\&, AND A D ROSES

From * the Departments of Human Genetics and †Biostatistics, University of Michigan, Ann Arbor, Michiga? 48109-0618; $\ddagger$ the Division of Neurology, Department of Medicine, Duke University Medical Centers Durham, North Carolina 27710, and \$the Department of Pediatrics and the Biological Sciences Researc Center, University of North Carolina, Chapel Hill, North Carolina 27514, USA.

SUMMARY Linkage relationships of the gene for peripheral neurofibromatosis (NF) were assessed in a large American Caucasian pedigree using two DNA markers located on

Received for publication 26 March 1987. Accepted for publication 27 March 1987 chromosome 8 . Linkage to the thyroglobuli locus, located at $8 \mathrm{q} 24$, was excluded (log $<-2 \cdot 0)$ to $21 \mathrm{cM}$. Data obtained for the tissue plasminogen activator locus, located at $8 \mathrm{p} 1 \frac{0}{2}$ excluded linkage to $4 \mathrm{cM}$. These results ex@ clude between 20 to $30 \%$ of chromosome 8 as a possible map location for the NF gene in this 
family. Comparison of the two DNA markers excluded their linkage to $0.5 \mathrm{cM}$.

As documented in the accompanying papers, the exclusion map for the location of the gene responsible for peripheral neurofibromatosis is becoming substantial. We have been investigating the possibility that this gene is located on chromosome 8 , a chromosome for which until recently very few markers were available. This chromosome is of interest for two reasons. (1) It is the site of two known oncogenes, the mos and myc protooncogenes. (2) NF has recently been observed in association with a potentially de novo complex chromosomal rearrangement (Kittur, Valle, and Kazazian, personal communication) involving chromosomes $1 \mathrm{q}, 8 \mathrm{q}$, and $15 \mathrm{q}$ with two breakpoints on 8q. The affected subject, a 13 year old female, exhibits symptoms of NF including multiple café au lait spots, macrocephaly, and thoracolumbar scoliosis. While the presence of features of NF could represent the simultaneous but unrelated occurrence of two different genetic conditions in the child, it is also possible that one of the breakpoints involved in the rearrangement has interrupted or activated a gene which is responsible for NF. In a possibly related observation, Palmer et $a l^{1}$ have recently reported a child with trisomy 8 mosaicism who developed features consistent with $\mathrm{NF}$ as well as chronic granulocytic leukaemia. Although this evidence is highly circumstantial, it can be regarded as useful in that it suggests possible chromosomes on which to seek linkage.

We are also concerned about the possibility of locus heterogeneity in NF. Therefore, we have chosen to do our linkage analyses using a very large American Caucasian pedigree segregating for NF, in order to avoid the risk of failing to detect linkage due to pooling families that have different loci responsible for the NF disease phenotype.

\section{Methods}

The pedigree segregating for NF used in this study and the criteria for diagnosis of NF are described elsewhere. $^{2}$

DNA was isolated either directly from venous blood or from EBV transformed B lymphocyte cultures. ${ }^{2}$ Restriction endonuclease digestions, agarose electrophoresis, and Southern blotting were carried out using standard methods. ${ }^{3}$ Linkage to NF was tested for two DNA markers located on chromosome 8 that exhibit restriction fragment length polymorphisms. We used a genomic DNA clone containing part of the thyroglobulin (TG) locus (pCHT16/8.0) that has been mapped to $8 \mathrm{q} 24^{4}$ to detect a two allele TaqI polymorphism. ${ }^{4}$ We also used a cDNA clone (pTPA) containing the entire coding region of the tissue plasminogen activator (PLAT) locus. This gene has been mapped to $8 \mathrm{p} 12^{5}$ and detects a two allele EcoRI polymorphism. ${ }^{6}$

Since both DNA markers used here are located on chromosome 8 , we also assessed linkage between these marker loci in order to begin to develop a linkage map for this chromosome. Adult subjects of uncertain NF diagnosis were not included in the NF linkage analysis. Prepubescents were also excluded from the NF linkage analysis, because of the age dependent penetrance of this disease. ${ }^{7}$ Both of these groups were used in the analysis of linkage between the two DNA markers. Therefore, for evaluating linkage to NF, we used 45 subjects ( 25 affected) with known TG genotypes and 36 subjects (19 affected) with known PLAT genotypes. Genotypes were determined for 44 subjects for both TG and PLAT irrespective of NF status, and these were used for assessing linkage between these DNA markers.

Linkage to NF was assessed by the method of lod scores $^{8}$ using the programme LIPED. ${ }^{9}$ The following allele frequencies were used in our analyses: 0.8 for the $5.2 \mathrm{~kb}$ TG allele ${ }^{4} ; 0.5$ for both PLAT alleles; and 0.0003 for NF. ${ }^{7}$ We assumed penetrance of $95 \%$ for NF for post-pubescent subjects. Equal recombination fractions were assumed for males and females. An estimate of the number of potentially informative meioses within this complex pedigree is discussed elsewhere. ${ }^{2}$ Customarily, a lod score less than $-2 \cdot 0$ is considered sufficient to exclude linkage between loci. ${ }^{8}$

\section{Results}

Lod scores estimating linkage between each of the DNA markers and NF and between the two DNA markers are presented in the table. Linkage to NF can be excluded up to a recombination fraction of 0.21 for the TG locus and 0.04 for the PLAT locus. Additional analyses indicated that inclusion of apparently unaffected prepubescent subjects and the assumption of $100 \%$ penetrance for NF among adults had only small effects on lod scores.

TABLE Lod scores testing linkage of chromosome 8 DNA markers to the NF locus and each other.

\begin{tabular}{lllllllr}
\hline Loci & & $\theta$ & & & & & \\
\cline { 3 - 7 } & & 0.0 & 0.05 & 0.1 & \multicolumn{1}{l}{0.2} & \multicolumn{1}{l}{0.3} & \multicolumn{1}{c}{0.4} \\
\hline NF & TG & $-\infty$ & -5.93 & -4.35 & -2.23 & -1.01 & -0.31 \\
NF & PLAT & -10.32 & -1.88 & -0.88 & 0.07 & 0.16 & 0.13 \\
TG & PLAT & $-\infty$ & -0.69 & -0.23 & 0.12 & 0.17 & 0.19 \\
\hline
\end{tabular}


Linkage of the TG and PLAT loci to each other can be excluded up to a recombination fraction of $0 \cdot 005$. These relatively small recombination fractions are converted into essentially equal genetic map distances by applying any of the commonly used mapping functions that allow for interference. The smaller range of exclusion associated with both linkage tests involving the PLAT marker is attributable to the smaller sample of subjects at this locus and the occurrence of fewer informative heterozygotes among those subjects sampled.

\section{Discussion}

The results of this linkage study exclude a significant portion of chromosome 8 as the potential site of the NF locus. Since the entire human genorne consists of about $3300 \mathrm{cM}$ of map distance, ${ }^{10}$ and since chromosome 8 is an average size chromosome, we estimate that chromosome 8 spans about $150 \mathrm{cM}$ of map distance. If the TG locus is actually located very close to the telomere in $8 \mathrm{q} 24$, we can only exclude linkage to NF in one direction. However, if it is located more proximally, our data would permit exclusion of $21 \mathrm{cM}$ on either side of this locus. Since the PLAT marker excludes linkage in both directions, the combination of these DNA markers excludes between 29 to $50 \mathrm{cM}(20$ to $30 \%)$ of chromosome 8 . The application of additional chromosome 8 markers to this NF pedigree is therefore necessary to exclude this chromosome fully as a potential location for the NF gene.

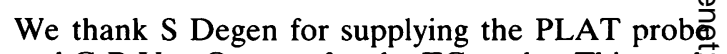
and G B Van Ommen for the TG probe. This work: was supported by NIH grant NS23410.

\section{References}

1 Palmer CG, Provisor AJ, Weaver DD, et al. Juvenile chroniō granulocytic leukemia in a patient with trisomy 8 , neurofibroma $\vec{D}$ tosis, and prolonged Epstein-Barr virus infection. J Pediat 1983;102:888-92.

2 Pericak-Vance MA, Yamaoka LH, Vance JM, et al. Linkage studies in peripheral neurofibromatosis. J Med Genet 1987;24仓 530-2.

3 Davis LG, Dibner MD, Battey JF. Basic methods in molecula $\vec{\omega}$ biology. New York: Elsevier, 1986.

4 Baas F, Bikker H, Geurts van Kessel A, et al. The humaम̄ thyroglobulin gene: a polymorphic marker localised distal to myc on chromosome 8 band q24. Hum Genet 1985;69:138-43. iv

5 Yang-Feng TL, Opdenakker G, Volckaert G, Francke U Human tissue-type plasminogen activator gene located near chromosomal breakpoint in myeloproliferative disorder. $A m$. Hum Genet 1986;39:79-87.

6 Benham FJ, Spurr N, Povey S, et al. Assignment of tissue-type plasminogen activator to chromosome 8 in man and identification of a common restriction length polymorphism within the gene $\mathcal{S}$

Mol Biol Med 1984;2:251-9.
7 Crowe FW, Schull WT, Neel JV. Multiple neurofibromatosis $\frac{\Phi}{\frac{\Phi}{O}}$ Springfield, Illinois: C C Thomas, 1956.

$\therefore$ Morton NE. Sequential tests for the detection of linkage. $\mathrm{Am}$ Hum Genet 1955;7:277-318.

${ }^{9}$ Ott J. A computer program for linkage analysis of general. human pedigrees. Am J Hum Genet 1976;28:528-9.

10 Renwick JH. The mapping of human chromosomes. Annu \&ew Genet 1971;5:81-120.

Correspondence ąnd requests for reprints to $\mathrm{Dr}$ Diehl, Department of Human Genetics, Universit of Michigan Medical School, Medical Science If M4708/0618, 1500 E Medical Center Drive, An Arbor, Michigan 48109-0618, USA.

\title{
Further exclusion data for the Von Recklinghausen neurofibromatosis gene: a genetic linkage study of 19 polymorphie markers
}

\author{
MEENA UPADHYAYA*, MANSOOR SARFARAZI*, \\ SUSAN M HUSON†, AND PETER S HARPER*
}

From *the Institute of Medical Genetics, University of Wales College of Medicine, Heath Park, Cardif CF4 4XN; and the Division of Inherited Metabolic Diseases, Clinical Research Centre, Watford Road Harrow, Middlesex HAl $3 U J$.

SUMMARY Linkage analysis on a panel of 15 Von Recklinghausen neurofibromatosis (VRNF) families with 19 polymorphic markers was carried out using the computer programme M-Link. Our findings have excluded VRNF from a significant proportion of the genome.
Von Recklinghausen neurofibromatosis (VRNF) is one of the commonest autosomal dominant disi orders in man with a prevalence of at leasi $20 / 100000^{1}$ of the population. The mapping of the VRNF gene will be an important step towards ouf eventual understanding of the pathogenesis of thक्ष disease and a closely linked marker would b $\vec{e}$ immediately applicable in prenatal diagnosis whero appropriate. 